\title{
EDITORIAL
}

\section{Placental examination: a challenge for pathologists}

Paulo Roberto Merçon de Vargas*

The importance of the placenta as the organ that provides maternal supplies to the fetus has been recognized since the ancient Egyptians $^{(3)}$. Experts in placental pathology are unanimous in pointing out the clinical, pathological and epidemiological relevance of the lesions of this unique organ. Little is acknowledged as to the practical contribution of its examination by obstetricians, pediatricians and pathologists. Quite few placentas have been examined by pathologists.

There are many reasons for this discouraging situation: the inherent difficulty in examining a complex organ, the unpleasant task of a mostly gross examination, the lack of consensus for its nosology and the low motivation to grasp a post factum problem. However, recent progress in biology and pathology of reproduction has brought to light the practical relevance of placental examination.

Considerable progress has been achieved through the acknowledgement that placental features reveal the uterine environment and may aid to detect adult diseases. Since the pioneering Barker's proposal, many reports have correlated features of the uterine fetal environment with cardiovascular and metabolic chronic disorders among other health conditions and adult diseases ${ }^{(1,6)}$. This proposed pathogenesis for adult chronic diseases has been named Developmental Origin of Health and Adult Diseases (DOHAD) or Barker hypothesis ${ }^{(6)}$. According to this model, the causes to be identified could lead directly or through changes in placental structure and function to altered (reduced, augmented or qualitatively abnormal) substrate availability to the developing fetus. This altered condition could permanently change gene expression and the function of a few key systems linked to chronic adult disease, including the immune system, antioxidant defenses, inflammatory responses, and the number and quality of stem cells ${ }^{(1)}$.

Among these uterine environment features, it is notably worth mentioning the placental size and shape abnormalities, which were until recently subject to only a cursory pathological examination. However, Salafia et al. ${ }^{(10,11,13)}$ proposed that the placental growth and shape are features that provide a fractal structure of fetal vessels to optimize the extraction of oxygen and nutrients from the maternal supply line in order to support the fetal development. Accordingly, abnormal placental shapes and size both reveal maternal supply line deprivations and are associated with reduced placental efficiency. The relevance of diagnosing these lesions for clinical managing and the possibility of any of these chronic effects being reversed after birth are still unclear. Much controversy surrounds this topic, but the challenge is to examine, report, and include placental features in the medical records of all births.

Some progress has also been achieved in terms of nosology. A considerable difficulty in placental examination is to describe its features and lesions through a clear report, worded in standard and comprehensible pathological and clinical terms. Fortunately, recent efforts have been made to reach a consensus in placental nosology ${ }^{(7,8)}$ and format for pathology reports ${ }^{(12)}$. Without such nosology and standard terminology, the placental pathology report will continue to seem useless. These proposals, specially the papers from Redline ${ }^{(7,8)}$, are a must reading for all pathologists.

These achievements in understanding placental pathology and nosology may help us face the challenges of serious reproductive problems, including the growing occurrence of preterm births of the HIV and antiretroviral exposed fetus.

As an unintended consequence of the huge success in improving survival of preterm infants, we are now facing the emergence of its postnatal sequelae, including chronic pulmonary disease, retinopathy of prematurity, cerebral palsy

Adjunct Professor at Pathology Department of Universidade Federal do Espírito Santo (UFES), Vitória, Espírito Santo State, Brazil. 
and other neurological impairments. Several recent studies have linked most of these diseases to chorioamnionitis, specifically to the Fetal Inflammatory Response Syndrome (FIRS), characterized by funisitis, high blood interleukin-6 level, and neonatal sepsis-like syndrome ${ }^{(4,9)}$. Due to the lack of clinical signs, most cases of chorioamnionitis remain clinically and epidemiologically unidentified. However, an early postnatal diagnosis can be established within minutes by frozen section and placental smear ${ }^{(2)}$ in time to guide clinical intervention.

Accordingly, having attaining a great reduction in maternal-to-child transmission (MTC) of HIV by antiretroviral drugs (ART), we remain with the challenge to identify placental markers for HIV placental infection and MTC transmission and to understand the pathogenesis of the associated high occurrence of preterm births, fetal growth restriction and its postnatal consequences. Awaiting 18 months to confirm whether MTC transmission have occurred or not is utterly unacceptable. Indeed, the fact that a few studies have not found placental morphological markers of HIV infection and MTC transmission does not imply that placental pathological study is an unrewarding task. Before concluding that such major occurrences (maternal HIV infection, associated comorbidities and ART) have no morphological markers, we need to strive for further improvement.

In this issue of the Brazilian Journal of Pathology and Laboratory Medicine (JBPML), López et al.${ }^{(5)}$ report a study of HIV p24 protein expression in placental tissue and attempt to correlate its presence with placental lesions and MTC transmission. The results are not conclusive, but the authors should be congratulated on accepting the challenge.

In the "molecular age" of Medicine, it is worthwhile to be reassured that morphological analysis will continue to play its pivotal role in understanding human diseases.

\section{REFERENCES}

1. BARKER, D. J. et al. The obstetric origins of health for a lifetime. Clin Obstet Gynecol, v. 56, n. 3, p. 511-19, 2013.

2. BLANC, W. A. Pathology of the placenta, membranes, and umbilical cord in bacterial, fungal, and viral infections in man. Monogr Pathol, v. 22, p. 67-132, 1981.

3. BOYD, J. D. \& HAMILTON, W. The Human Placenta. Cambridge: W. Heffer and Sons, 1970.

4. GOTSCH, F. et al. The fetal inflammatory response syndrome. Clin Obstet Gynecol, v. 50, n. 3, p. 652-83, 2007.

5. LÓPEZ, C. L. et al. Characterization of placental pathology of women HIV+ associated with p24.J Bras Patol Med Lab, v. 49, n. 6, p. $\mathrm{xxx}, 2013$.

6. PANETH, N. et al. Early origin of coronary heart disease (the "Barker hypothesis"). BMJ, v. 310, n. 6977, p. 411-2, 1995.

7. REDLINE, R. W. et al. Amniotic infection syndrome: nosology and reproducibility of placental reaction patterns. Pediatr Dev Pathol, v. 6, n. 5, p. $435-48,2003$.

8. REDLINE, R. W. Placental pathology: a systematic approach with clinical correlations. Placenta, Suppl A:S86-91, 2008.

9. ROMERO, R. et al. Inflammation in pregnancy: its roles in reproductive physiology, obstetrical complications, and fetal injury. Nutr Rev, v. 12, n. 12 Pt 12, S194-202, 2007.

10. SALAFIA, C. M. et al. Allometric metabolic scaling and fetal and placental weight. Placenta, V. 30, n. 4, p. 355-60, 2009.

11. SALAFIA, C. M. et al. Placental surface shape, function, and effects of maternal and fetal vascular pathology. Placenta, v. 31, n. 11, p. $958-62,2010$.

12. TUROWSKI, G. et al. A new, clinically oriented, unifying and simple placental classification system. Placenta, v. 33, n. 12, p. 1026-35, 2012.

13. WINDER, N. R. et al. Mother's lifetime nutrition and the size, shape and efficiency of the placenta. Placenta, v. 32, n. 11, p. 806-10, 2011. 